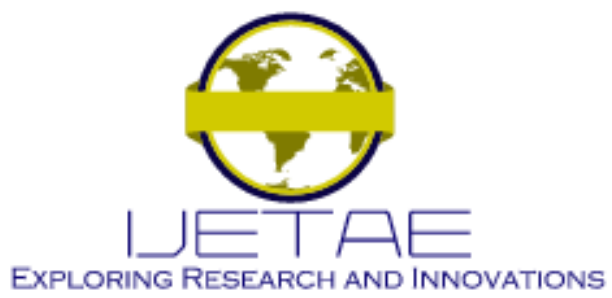

International Journal of Emerging Technology and Advanced Engineering

Website: www.ijetae.com (E-ISSN 2250-2459, Scopus Indexed, ISO 9001:2008 Certified Journal, Volume 11, Issue 08, August 2021)

Manuscript Received: 06 July 2021, Received in Revised form: 07 August 2021, Accepted: 12 August 2021

DOI: 10.46338/ijetae0821_11

\title{
A Review Paper on Automatic Text Summarization in Indonesia Language
}

\author{
Nurul Khotimah ${ }^{1}$, Adi Wibowo $\mathrm{P}^{2}$, Bryan Andreas ${ }^{3}$, Abba Suganda Girsang ${ }^{4}$ \\ ${ }^{1,2,3,4}$ Computer Science Department, BINUS Graduate Program - Master of Computer Science, Bina Nusantara University, \\ Jakarta, Indonesia 11480
}

\begin{abstract}
Text summarization is one problem in natural language processing that generates a brief version of the original document. This research took attention for some researchers in this last decade and growing fast, including Indonesia language. This paper aims to recap summarization text research especially in Indonesia language. As usual, this paper discusses two summarization approaches, extractive and abstractive. In fact, the number of research of extractive is more than abstractive. This paper investigates some methods such as Statistical Based Approach, Graph Based Approach, Machine Learning Approach, Fuzzy Logic Approach, Algebraic Approach, and Hybrid Approach. This paper shows some methods details and summarize the results.
\end{abstract}

Keywords - Text summarization, extractive summary, abstractive summary, natural language processing.

\section{INTRODUCTION}

Nowadays, digital information such as e-Newspaper, journal article, transcript dialogues and information from social media are huge and increase day by day. Therefore, the need of text summarization machine even more obvious and needed to be able to assist us in getting information from the source data in less time than having to read the whole document. Text summarization is a treatment to shrink the documents into smaller with keeping the meaning. Text summarization is one of those applications of Natural Language Processing (NLP) that generating a concise summary of text from single or multiple document such as books, news article, tweets, transcript dialogue, and research paper. Another case is when a news editor wants to summarize multiple news articles by clustering the information from different media and summarize them.

There are two types in text summarization: extractive and abstractive. Most of recent study of text summarization either in English or Indonesian has focus on extractive summarization because it easier than abstractive summarization.
The extractive summarization choose some sentences from the whole original documents. The summarization is calculated with a function. The abstractive summarization produces summary by interpreting the text using advance techniques. This summary is generated by form some sentences which human rearranges with the new sentences or phrase. This summarization can be generated not only from some parts of the original document, but also can be from the outside word of the original document. The more important is the summarization has the same meaning with the original one.

In summarizing the text, humans usually read the entire document and then take the important points. Text summarization research is very interesting, and not trivial because computers do not have human-like abilities. There are many approaches taken to solve the problem of summary text.. In this paper, we reviewed the details of various recent approach on automatic text summarization for Indonesian language. We focused on methodologies used to generate a summary and what algorithms are used under each methodology. It also discussed how far the development of research in the field of Indonesian text summarization, so it can be a good reference for further research to increase the result and accuracy of generated summary.

The rest of this paper is organized as follows. Section 2 presents a review of text summarization process. Section 3 presents a review of automatic text summarization approach. Section 4 presents the discussion automatic text summarization methodologies of research publication. Section 5 present issue and challenge in text summarization. Finally, the conclusion with future direction is drawn in Section 6. 


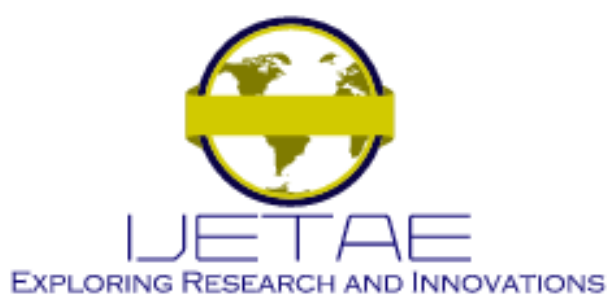

International Journal of Emerging Technology and Advanced Engineering

Website: www.ijetae.com (E-ISSN 2250-2459, Scopus Indexed, ISO 9001:2008 Certified Journal, Volume 11, Issue 08, August 2021)

TABLE I

CATEGORIZATION OF TEXT SUMMARIZATION APPROACHES

\begin{tabular}{|c|c|c|c|c|}
\hline \multicolumn{5}{|c|}{ Text Summarization Approach } \\
\hline $\begin{array}{c}\text { Statistical } \\
\text { Based }\end{array}$ & $\begin{array}{l}\text { Graph } \\
\text { Based }\end{array}$ & $\begin{array}{l}\text { Machine } \\
\text { Learning }\end{array}$ & $\begin{array}{l}\text { Fuzzy } \\
\text { Logic }\end{array}$ & Algebraic \\
\hline $\begin{array}{l}\text { Term } \\
\text { Frequency }\end{array}$ & $\begin{array}{l}\text { Test } \\
\text { Rank }\end{array}$ & $\begin{array}{l}\text { Naïve } \\
\text { Bayes }\end{array}$ & $\begin{array}{l}\text { Mamdan } \\
\text { i }\end{array}$ & $\begin{array}{l}\text { Non-Negative } \\
\text { Matrix } \\
\text { Factorization } \\
\text { (NMF) }\end{array}$ \\
\hline $\begin{array}{l}\text { Term } \\
\text { Frequency } \\
\text { - Inverse } \\
\text { Document } \\
\text { Frequency }\end{array}$ & $\begin{array}{l}\text { PageRan } \\
\mathrm{k}\end{array}$ & $\begin{array}{l}\text { Decision } \\
\text { Tree }\end{array}$ & $\begin{array}{l}\text { Latent } \\
\text { Semanti } \\
\mathrm{c} \\
\text { Analysis }\end{array}$ & $\begin{array}{l}\text { Singular } \\
\text { Value } \\
\text { Decompositio } \\
\mathrm{n} \text { (SVD) }\end{array}$ \\
\hline $\begin{array}{l}\text { Text } \\
\text { Teaser }\end{array}$ & & $\begin{array}{l}\text { Bidirectiona } \\
1 \text { Gated } \\
\text { Recurrent } \\
\text { Unit }\end{array}$ & & \\
\hline
\end{tabular}

\section{RELATED WORK}

Summarization can be classified into two based types. The first type is based on characteristic, extractive and abstractive and the second type is based on number document (single or multiple).

Abstractive text summarization is a technique to construe the original document to new document which can be different literally but the same in meaning in the context of the sentence. Adelia et al. [1] developed an abstractive summarization generate summary from Indonesian language journal documents that will be assigned as abstract. Extractive text summarization method generates a summary by taking some sentences from the original documents. This chosen sentences are considered as a representation of whole documents. This method gives a score for each sentences which depicts the significant meaning. Then it calculates with analysis statistic to determine which sentences are chosen [2][3][4]. Single document text summarization is built by produce produce a single output document [4]. In multiple document text summarization, summarization is built based on more than one document, and all of them are of the same topic. Gunawan et al. [5] developed automatic text summarization for online news articles which are separated into six categories. Each category which comprises five articles with the same topics are then summarized.
This study proposed combining TextRank + MMR to overcome the problem of the similarity text when merges multi-document.

\section{METHODOLOGY}

This study is a systematic literature review (SLR) about text summarization in Indonesia language. The purpose of SLR is to provide answers to specific research questions by identifying, evaluating and interpreting the overall results of research summarization text in Indonesia language [6].

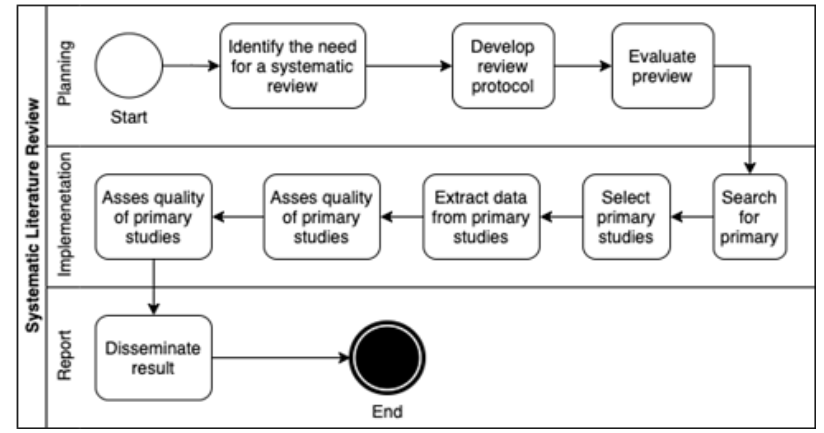

Figure 1 Systematic literature review steps

Figure 1 shows some steps of method SLR. They are planning, implementation and last reporting [7]. This investigation gives some findings. This paper is able to answer some important questions such as. What are the most frequently used methods/approaches in text summarization of Indonesia language? What are the most frequently used characteristics/techniques in text summarization of Indonesia language? What is the most frequently used document type in text summarization of Indonesia language?

Data sources used in this paper are searched from leading paper journal and conferencing site include schoolar.google.com, sciencedirect.com, and ieeexplore.com. To get the suitable papers that fit the topic, the searching process is conducted based on specific keywords or synonyms of the keywords. The search string used in searching process is: (Indonesian text summarization OR Indonesian abstractive text summarization OR Indonesian extractive text summarization) AND (approach, OR technique OR method). To reduce unrelated studies, adjustment of search string is conducted.

From the search results, the main paper articles that will be summarized are determined based on inclusion criteria. The inclusion criteria are: 


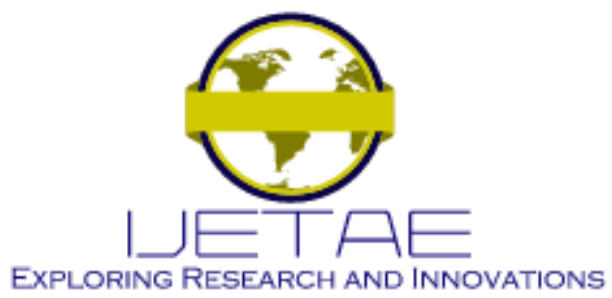

International Journal of Emerging Technology and Advanced Engineering

Website: www.ijetae.com (E-ISSN 2250-2459, Scopus Indexed, ISO 9001:2008 Certified Journal, Volume 11, Issue 08, August 2021)

- Publication year: 2009 - 2020

- Studies summarize Indonesian text include topics, techniques and methods used.

- Studies written in English or Indonesian.

Publications reviewed are $82 \%$ journaled papers and $18 \%$ of conferences. Conference papers are also included as it also contains some meaningful insight about the topic. As the topic is specific for text summarization of Indonesian language, the paper articles included are limited to paper articles in English and Indonesian. Finally, based on inclusion criteria, 19 papers are chosen to be summarized and reviewed in this paper. After investigation, we found 5 approaches in summarization text as shown in Table 1.

\section{ANALYSIS TEXT SUMmariZATION}

Table 2 shows the previous study of summarization text in Indonesia language.

\section{A. Statistical Based Approaches}

Prasetya et al [8] proposed SIDoBI (Sistem Ikhtisar Dokumen for Bahasa Indonesia) or Indonesian Language Document Summarization System.
This is an extractive summarization which uses IDF dictionary (English to Indonesia). This system is developed using mead Perl and PHP language and able to run in web server. The IDF dictionary is used for the generating the score each word to identify which sentences is important. Furthermore, each sentence will be ranked according to its level of importance. A summary is compiled using the most important sentences until the length requested by the user is met. The result indicates that accuracy of using IDF English outperforms than using IDF Indonesia.

Fachrurrozi et al. [2] proposed frequent term based method. They judged that noun and verb word are the most represent of meaning in sentences. They convert each sentence into weight value based on number of noun and verb word. The higher value is higher candidate to choose as a summary. This study also combined statistic method and fundamental sentences. They are the title and position of sentence. The sentences extracted are taken from the third top and bottom of the paragraph. Moreover, the last or first paragraph will be considered as big weight. 


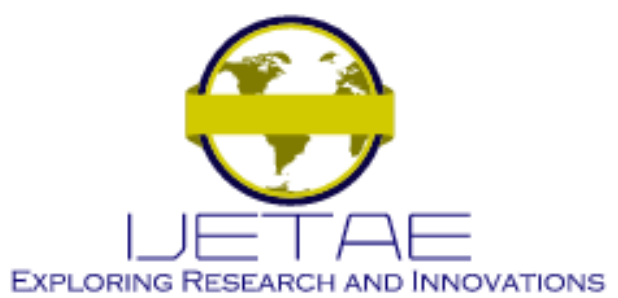

International Journal of Emerging Technology and Advanced Engineering

Website: www.ijetae.com (E-ISSN 2250-2459, Scopus Indexed, ISO 9001:2008 Certified Journal, Volume 11, Issue 08, August 2021)

TABLE II

PREVIOUS STUDIES ON AUTOMATIC TEXT SUMMARIZATION IN BAHASA INDONESIA

\begin{tabular}{|c|c|c|c|c|c|c|}
\hline Year & Study & Type of Approach & Characteristic & Document & $\begin{array}{c}\text { Used Algorithm / } \\
\text { Techniques }\end{array}$ & Comments \\
\hline 2009 & {$[17]$} & Statistical based approach & Extractive & Single & Genetic Algorithm & $\begin{array}{l}\text { Advantage: Simple and unsupervised } \\
\text { approaches, no need for training dataset }\end{array}$ \\
\hline 2012 & {$[20]$} & Statistical based approach & Extractive & Single & Genetic Algorithm & $\begin{array}{l}\text { Advantage: Simple and unsupervised } \\
\text { approaches, no need for training dataset }\end{array}$ \\
\hline 2013 & {$[15]$} & Algebraic Approach & Extractive & Single & Latent Semantic Analysis & $\begin{array}{l}\text { Advantage: Generated summary provide } \\
\text { semantic relation. }\end{array}$ \\
\hline 2013 & {$[2]$} & Statistical based approach & Extractive & Single & $\begin{array}{lll}\begin{array}{l}\text { Frequent } \\
\text { Method }\end{array} & \text { Term } & \text { Based } \\
\end{array}$ & $\begin{array}{l}\text { Advantage: Generated summary reflects } \\
\text { the important word for the document. }\end{array}$ \\
\hline 2013 & [14] & Fuzzy Logic Approach & Extractive & Single & Fuzzy & $\begin{array}{l}\text { Advantage: Generated summary reduce } \\
\text { redundancy. }\end{array}$ \\
\hline 2014 & [3] & Hybrid Approach & Extractive & Single & $\begin{array}{l}\text { Latent Dirichlet Allocation } \\
\text { and Genetic Algorithm }\end{array}$ & $\begin{array}{l}\text { Advantage: Generated summary relevant } \\
\text { and consistent with the original document }\end{array}$ \\
\hline 2014 & {$[16]$} & Algebraic Approach & Extractive & Single & $\begin{array}{l}\text { Non-Negative } \quad \text { Matrix } \\
\text { Factorization }(\mathrm{NMF})\end{array}$ & $\begin{array}{l}\text { Advantage: Using semantic feature the } \\
\text { generated summary present important } \\
\text { information. }\end{array}$ \\
\hline 2014 & {$[18]$} & Hybrid Approach & Extractive & Multiple & $\begin{array}{l}\text { Latent Semantic Analysis + } \\
\text { WordNet }\end{array}$ & $\begin{array}{l}\text { Advantage: Reduce redundancy of } \\
\text { sentences. }\end{array}$ \\
\hline 2015 & [19] & Hybrid Approach & Extractive & Single & $\begin{array}{l}\text { Latent Dirichlet Allocation } \\
\text { (LDA) }\end{array}$ & Advantage: Suitable for large dataset. \\
\hline 2015 & {$[21]$} & Algebraic Approach & Extractive & Single & $\begin{array}{l}\text { Singular } \\
\text { decomposition }\end{array}$ & $\begin{array}{l}\text { Advantage: SVD has capability of } \\
\text { modelling relationships among words } \\
\text { and sentences, and noise reduction which } \\
\text { helps to improve accuracy. }\end{array}$ \\
\hline 2015 & [11] & Machine Learning Approach & Extractive & Single & Naïve Bayes & $\begin{array}{l}\text { Advantage: Supervised approach that } \\
\text { can be easily to learn and detect } \\
\text { important features of the sentences. }\end{array}$ \\
\hline 2016 & [9] & Statistical Based Approach & Extractive & Single & $\begin{array}{l}\text { Term Frequency-Inverse } \\
\text { Document Frequency (TF- } \\
\text { IDF) }\end{array}$ & Advantage: Efficient in computations. \\
\hline 2017 & [12] & Machine Learning Approach & Extractive & Single & Decision Tree & $\begin{array}{l}\text { Advantage: } \\
\text { performance of a high number of } \\
\text { features. }\end{array}$ \\
\hline 2017 & {$[10]$} & Statistical Based Approach & Extractive & Single & TextTeaser & $\begin{array}{l}\text { Advantage: Unsupervised and language } \\
\text { independent or adaptability with any } \\
\text { language. }\end{array}$ \\
\hline 2017 & {$[13]$} & Statistical Based Approach & Extractive & Single & Vector Space Model & $\begin{array}{l}\text { Advantage: Simple and unsupervised } \\
\text { approaches. Cosine similarity feature } \\
\text { resulted in summary by text coherence. }\end{array}$ \\
\hline 2019 & {$[22]$} & Hybrid Approach & Extractive & Single & $\begin{array}{l}\text { Multi-Objective Ant Colony } \\
\text { Optimization }+ \text { PageRank } \\
\text { Algorithm }\end{array}$ & $\begin{array}{l}\text { Advantage: MOACO can produce } \\
\text { informative and concise summaries. }\end{array}$ \\
\hline 2019 & [1] & Machine Learning Approach & Abstractive & Single & $\begin{array}{l}\text { Bidirectional } \quad \text { Gated } \\
\text { Recurrent Unit }\end{array}$ & $\begin{array}{l}\text { Advantage: Generated summaries are } \\
\text { influenced by the surrounding words. }\end{array}$ \\
\hline 2019 & [5] & Graph Based Approach & Extractive & Multiple & $\begin{array}{l}\text { TextRank }+\underset{\text { Maximal }}{ } \\
\text { Marginal Relevance }\end{array}$ & $\begin{array}{l}\text { Advantage: Generated summary } \\
\text { coverage good information and reduce } \\
\text { redundancy. }\end{array}$ \\
\hline 2019 & {$[23]$} & Hybrid Approach & Extractive & Multiple & $\begin{array}{l}\text { Semantic Clustering }+ \\
\text { Latent Dirichlet Allocation }\end{array}$ & $\begin{array}{l}\text { Advantage: Semantic Clustering is } \\
\text { being able to find semantic relations in } \\
\text { creating sentence clusters. }\end{array}$ \\
\hline
\end{tabular}




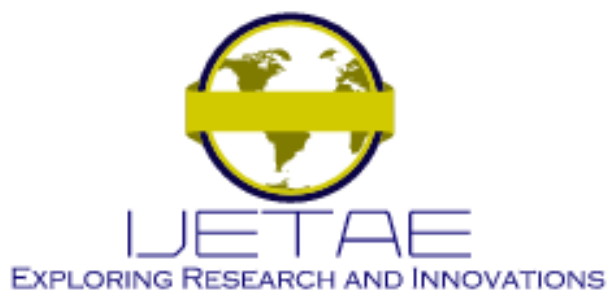

International Journal of Emerging Technology and Advanced Engineering Website: www.ijetae.com (E-ISSN 2250-2459, Scopus Indexed, ISO 9001:2008 Certified Journal, Volume 11, Issue 08, August 2021)

Another study by Christian et al. [9] also applied TFIDF algorithm as a weighting factor. This method calculated TF-IDF value of each word in documents. Each noun and verbal word are calculated to produce the important statement. Each sentence is then sorted based on the score. Compression size can be determined by user. This compression will form the number of sentences resulting from the summarization process. Gunawan et al. [10] presented text summarization using TextTeaser in Bahasa Indonesia documents, It selects the best sentences among text by calculating title feature, sentence length, sentence position and keyword frequency. Slamet et al [13] convert documents text into two values. The first is weight of word which is represented TF-IDF value and the second one is vector space model (VSM). This VSM is used to similarity between the sentences and keywords. This cosine similarity was used in this case. As a result, the sentences will be ordered by number of frequencies which is identified as important or summarization documents.

\section{B. Graph Based Approaches}

There are two important things in graph theory. Nodes and edges which connect between nodes. In summarization text, sentences are represented nodes and the value connection is represented edges. Gunawan et al [5] extract the original document uses TextRank algorithm to get the summarization. They also implemented Maximal Marginal Relevance (MMR) to cut the similar sentences. It is done because the previous summarization comprised the similarity text document.

\section{Machine Learning Based Approaches}

Machine learning approach utilizes training datasets to train the model and testing datasets to test the model. This model is then used to process input data and produce the output based on the trained model.

The important step in machine learning step is to set the features in the model. For text summarization, features are selected from the texts. Najibullah [11] defined some features of similarity text as follows. Author labelled the each of the sentences into two classes, whether it is an extractive sentence or not extractive sentence. If one sentence is labelled as extractive, it means this sentence is considered as one of the result summarization candidates. In this proposed method, the model is built by training the data sets using naïve bayes algorithm. The result of this model that tested with test data model performs evenly well.
Sabuna and Setyohadi [12] proposed eight features in the process summarization. Each sentence is scored based on those eight features. Decision trees are then used to build the machine learning model and determine the important sentences that is used in the output summary.

Adelia et al. [1] used Bidirectional GRU to consider the score between abstract and original text. This proposed method uses abstractive text summarization which generates new summary text based on important points/context. RNN method has proven to produce great result in the past on abstractive text summarization on other languages as well. This author utilizes Bidirectional Gated Recurrent Unit (BiGRU) RNN to keep the resulted summaries influenced by the surrounding words.

\section{Fuzzy Based Approaches}

For selecting sentences this approach uses fuzzy dependent on the features [14], the extraction method was applied by weighting the sentences which obtained 6 features in each sentence, including the feature title, sentence length, term weight, sentence position, sentence to sentence similarity and numerical data. The results of the value of each feature are used as fuzzy value input using the mamdani inference model. In the mamdani inference process, these rules are used in decision making using the Min-Max method. Then the composition function used is the Max function.

\section{E. Algebraic Approaches}

Tardan et al proposed semantic analysis to get the similarity between sentence and the title [15]. It is calculated by convert the document into vector values. The weight of every word to calculate the word similarity using Wordnet.

Text summarization can be produced by using some formulas. This way removes the trivial information with retain the core information of document. Nonnegative matrix factorization (NMF) Algorithm [16] is carried out by a partial grouping technique that identifies semantic features in a document collection and classifies documents into clusters based on their semantic features.

Singular Value Decomposition (SVD) extract a matrix to constituent parts matrix. The result of summarization has a good precision and recall in high level summarization.

\section{F. Hybrid Approaches}

Aristotoles et al [17] extracted sentences into eleven features in process summarization text. 


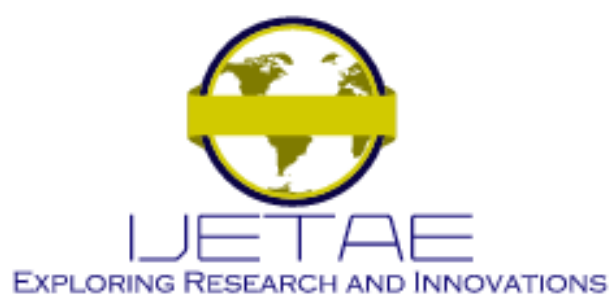

International Journal of Emerging Technology and Advanced Engineering

Website: www.ijetae.com (E-ISSN 2250-2459, Scopus Indexed, ISO 9001:2008 Certified Journal, Volume 11, Issue 08, August 2021)

They seek the optimal weight of combination of eleven features using genetic algorithm. As a result, they found that only four features have a good performance. They are positive keywords in sentence (f2), sentence centrality (f4), sentence resemblance to the title (f5), and latent semantic feature (f11).

Silvia et al. [3] proposed method of combining Latent Dirichlet Allocation (LDA) and Genetic Algorithm (GA). To handle problem in Indonesia language, they modified LDA which substituted the stemming and other variations. Sentence feature weight is calculated using GA approach.

Yapinus et al [18] combined the abstractive and extractive summarization. Abstractive summarization is get from wordnet and extractive summarization is get from title word. They sorted based on the high score of each paragraph. The score paragraph is computed based on their word similarity and with the title. This method ensure that there is no duplication by checking each paragraph which the highest score before the paragraph inserted.

Hidayat et al [19] used latent dirichlet allocation (LDA) to do extractive summarization. They used eleven features based method phase. A specified number of topics in a certain number before using LDA. Then each topics is classified based on the allocation word.

Lucky and Girsang [22] conducted Multi-Objective Ant Colony Optimization (MOACO) algorithm to produce the summarization. This study uses data from twitter comments. This system chose the important comments which is represent in graph model. The summarization depends on the ratio efficiency. Likewise, in multi objective problem, this study proposed two problems which are represented two functions that is contradicting. The first function is measuring cosine similarity, between the sentence and the centroid of its source text. Then the second function is the number words in sentences.

Lisjana et al [23] combined Latent Semantic Indexing (LSI) and Similarity-Based Histogram Clustering (SHC). It formed semantic sentence cluster. Then Latent Dirichlet Allocation (LDA) chose the sentences from the semantic sentence cluster which is formed before. The advantage of Semantic Clustering is being able to find semantic relations in creating sentence clusters. That is because the use of the Latent Semantic Indexing method before measuring sentence similarity values.

Hybrid, Machine Learning and Statistical Based approach are the most frequently used in Indonesian text summarization, as illustrated in figure 2 .

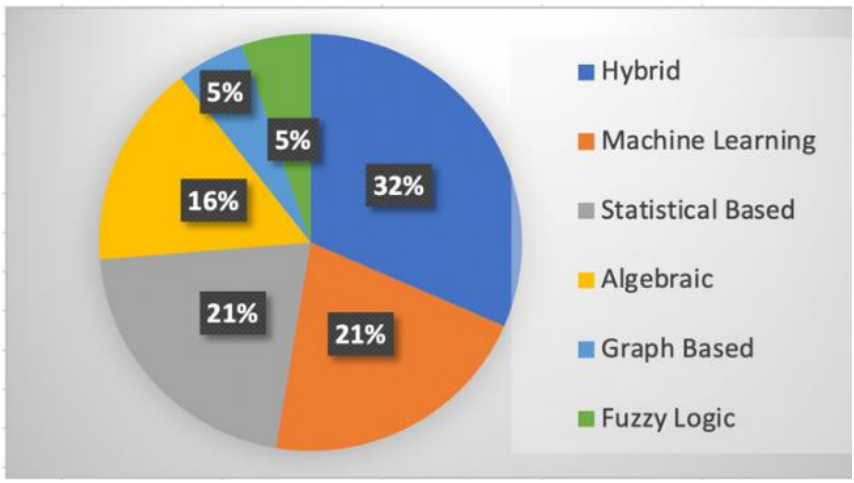

Figure 2 Most used approaches in text summarization

Most of reviewed previous studies in this paper used Extractive characteristic in text summarization, as shown in Figure 3.

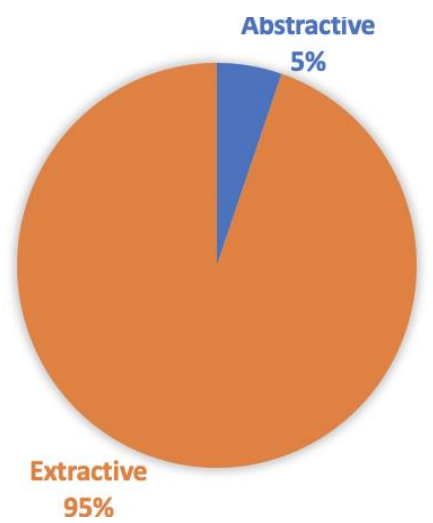

Figure 3 Distribution of text summarization characteristic

Figure 4 explains the distribution of used document type which shows single document type is the most frequently.

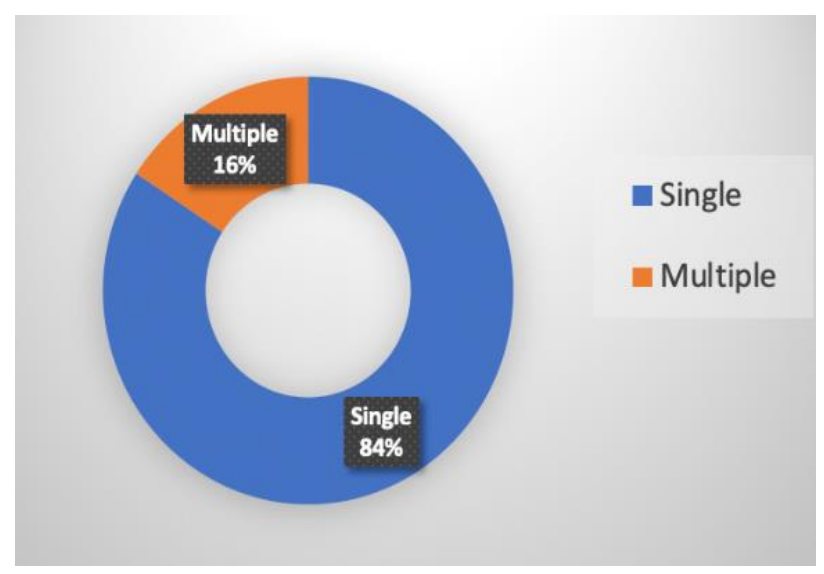

Figure 4 Distribution of document type 


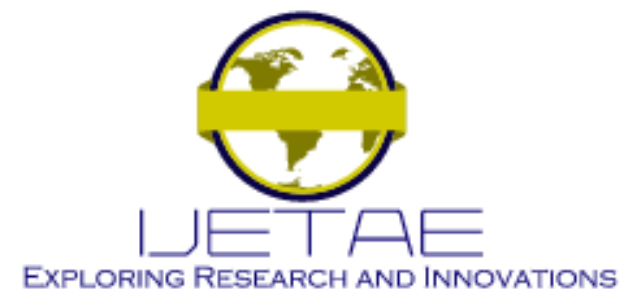

International Journal of Emerging Technology and Advanced Engineering Website: www.ijetae.com (E-ISSN 2250-2459, Scopus Indexed, ISO 9001:2008 Certified Journal, Volume 11, Issue 08, August 2021)

The main task of summarization is to solve the complexity of human language and the way people express themselves in written text. So, both extractive and abstractive method has their own challenges. Extractive summarization lacks the readability and coherence of the text produced while abstractive method is difficult and complex to be implemented. Beside its characteristic, text summarization has many approaches which introduce different challenge. [1] note that English text model still have higher ROUGE score when compared to Indonesian text model, which caused by the size of its text datasets and linguistic factor of Indonesian text model. The factor is quite vital especially for machine learning approach that rely on the size and quality of its datasets.

\section{CONCLUSION AND FUTURE WORK}

This paper reviews several approach and methodologies for text summarization in the Indonesian language. Based on time the method proposed, the algebraic and hybrid approach is the most frequent approach in the past, where text importance is mostly marked by the algorithm and its frequency. However, starting in 2015, machine learning approach becoming the trend for Indonesian text summarization. This method relies on training data to improve the accuracy of text summarization. Most of the research mentioned in this paper are using extractive techniques that extract parts from the text-based its importance and combine them to create a summary. The other types of text summarization output are Abstractive techniques, which catch important points and then generate new text from it. The abstractive text summarization requires more complex methods because it needs grammar and linguistic context to generate clear and readable output text summary. Abstractive text summarization is commonly done with a machine learning approach because it could train the model with data sets that contain targeted language and context closer to the testing set. However, more research still needs to be done to improve the accuracy and readability of abstractive text summarization results.

\section{REFERENCES}

[1] R. Adelia, S. Suyanto, and U. N. Wisesty, "Indonesian abstractive text summarization using bidirectional gated recurrent unit," Procedia Comput. Sci., vol. 157, pp. 581-588, 2019, doi: 10.1016/j.procs.2019.09.017.

[2] M. Fachrurrozi, N. Yusliani, and R. U. Yoanita, “ $\square$ Frequent Term based Text Summarization for Bahasa Indonesia,” pp. 30-32, 2013, doi: 10.15242/IIE.E1213550.
[3] Silvia, P. Rukmana, V. R. Aprilia, D. Suhartono, R. Wongso, and Meiliana, "Summarizing Text for Indonesian Language by Using Latent Dirichlet Allocation and Genetic Algorithm," Int. Conf. Electr. Eng. Comput. Sci. Informatics, vol. 1, no. August, pp. 148153, 2014, doi: 10.11591/eecsi.1.364.

[4] F. E. Gunawan, A. V. Juandi, and B. Soewito, "An automatic text summarization using text features and singular value decomposition for popular articles in Indonesia language," 2015 Int. Semin. Intell. Technol. Its Appl. ISITIA 2015 - Proceeding, pp. 27-32, 2015, doi: 10.1109/ISITIA.2015.7219948.

[5] D. Gunawan, S. H. Harahap, and R. Fadillah Rahmat, "Multidocument Summarization by using TextRank and Maximal Marginal Relevance for Text in Bahasa Indonesia," Proceeding - 2019 Int. Conf. ICT Smart Soc. Innov. Transform. Towar. Smart Reg. ICISS 2019, pp. 1-5, 2019, doi: 10.1109/ICISS48059.2019.8969785.

[6] C. Okoli and K. Schabram, "Working Papers on Information Systems A Guide to Conducting a Systematic Literature Review of Information Systems Research.”

[7] R. S. Wahono, "A systematic literature review of software defect prediction,” J. Softw. Eng., vol. 1, no. 1, pp. 1-16, 2015.

[8] B. Prasetyo, T. Uliniansyah, and O. Riandi, "SIDoBI: Indonesian Language Document Summarization System," Int. Conf. Rural Inf. Commun. Technol. 2009, no. 8, pp. 378-382, 2009, doi: 10.13140/2.1.1616.2083.

[9] H. Christian, M. P. Agus, and D. Suhartono, "Single Document Automatic Text Summarization using Term Frequency-Inverse Document Frequency (TF-IDF)," ComTech Comput. Math. Eng. Appl., vol. 7, no. 4, p. 285, 2016, doi: 10.21512/comtech.v7i4.3746.

[10] D. Gunawan, A. Pasaribu, R. F. Rahmat, and R. Budiarto, "Automatic Text Summarization for Indonesian Language Using TextTeaser,” IOP Conf. Ser. Mater. Sci. Eng., vol. 190, no. 1, p. 012048, Apr. 2017, doi: 10.1088/1757-899X/190/1/012048.

[11] A. Najibullah, "Indonesian Text Summarization based on Naïve Bayes Method," Int. Semin. Conf. 2015 Golden Triangle, pp. 6778, 2015.

[12] P. M. Sabuna and D. B. Setyohadi, "Summarizing Indonesian text automatically by using sentence scoring and decision tree," Proc. 2017 2nd Int. Conf. Inf. Technol. Inf. Syst. Electr. Eng. ICITISEE 2017, vol. 2018-Janua, pp. 1-6, 2018, doi: 10.1109/ICITISEE.2017.8285473.

[13] C. Slamet, A. R. Atmadja, D. S. Maylawati, R. S. Lestari, W. Darmalaksana, and M. A. Ramdhani, "Automated Text Summarization for Indonesian Article Using Vector Space Model," IOP Conf. Ser. Mater. Sci. Eng., vol. 288, no. 1, 2018, doi: 10.1088/1757-899X/288/1/012037.

[14] A. Ridok and T. C. Romadhona, "Peringkas Dokumen Otomatis Menggunakan Metode Fuzzy Model Sistem Inferensi Mamdani," Semin. Nas. Teknol. Inf. dan Multimed., pp. 19-24, 2013.

[15] P. P. Tardan, A. Erwin, K. I. Eng, and W. Muliady, "Automatic Text Summarization Based on Semantic Analysis Approach for Documents in Indonesian Language," in 2013 International Conference on Information Technology and Electrical Engineering (ICITEE), Oct. 2013, pp. 47-52, doi: 10.1109/ICITEED.2013.6676209. 


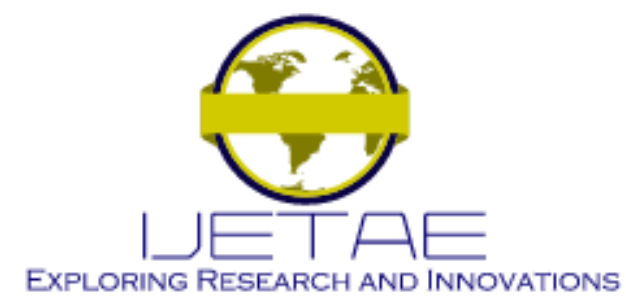

International Journal of Emerging Technology and Advanced Engineering

Website: www.ijetae.com (E-ISSN 2250-2459, Scopus Indexed, ISO 9001:2008 Certified Journal, Volume 11, Issue 08, August 2021)

[16] A. Ridok, "Peringkasan Dokumen Bahasa Indonesia Berbasis NonNegative Matrix Factorization (NMF)," J. Teknol. Inf. dan Ilmu Komput., vol. 1, no. 1, p. 39, 2014, doi: 10.25126/jtiik.201411104.

[17] A. Aristoteles, Y. Herdiyeni, and A. Ridha, "Text Feature Weighting for Summarization of Document Bahasa Indonesia Using Genetic Algorithm,” Int. J. Comput. Sci. Issues, vol. 9, no. 3, pp. 1-6, 2012.

[18] G. Yapinus, A. Erwin, M. Galinium, and W. Muliady, "Automatic Multi-Document Summarization for Indonesian Documents Using Hybrid Abstractive- Extractive Summarization Technique," Proc. 2014 6th Int. Conf. Inf. Technol. Electr. Eng. Leveraging Res. Technol. Through Univ. Collab. ICITEE 2014, pp. 0-4, 2014, doi: 10.1109/ICITEED.2014.7007896.

[19] E. Y. Hidayat, F. Firdausillah, K. Hastuti, I. N. Dewi, and Azhari, "Automatic Text Summarization Using Latent Drichlet Allocation (LDA) for Document Clustering," Int. J. Adv. Intell. Informatics, vol. 1, no. 3, pp. 132-139, 2015, doi: 10.26555/ijain.v1i3.43.
[20] Aristoteles, "Penerapan Algoritma Genetika pada Peringkasan Teks Dokumen Bahasa Indonesia," Semirata FMIPA Univ. Lampung, pp. 29-33, 2013.

[21] F. E. Gunawan, A. V. Juandi, and B. Soewito, "An automatic text summarization using text features and singular value decomposition for popular articles in Indonesia language," in 2015 International Seminar on Intelligent Technology and Its Applications (ISITIA), May 2015, pp. 27-32, doi: 10.1109/ISITIA.2015.7219948.

[22] Lucky and A. S. Girsang, "Multi-Objective Ant Colony Optimization for Automatic Social Media Comments Summarization," Int. J. Adv. Comput. Sci. Appl., vol. 10, no. 3, pp. 400-408, 2019, doi: 10.14569/IJACSA.2019.0100352.

[23] [O. A. Lisjana, D. P. Rini, and N. Yusliani, "Multi-Document Text Summarization Based on Semantic Clustering and Selection of Representative Sentences Using Latent Dirichlet Allocation,” vol. 172, no. Siconian 2019, pp. 203-206, 2020, doi: 10.2991/aisr.k.200424.029. 